\title{
Sobre Simmel e a guerra: escritos na imprensa alemã $^{1}$
}

\section{Simmel and the War: writings for the German Press}

\section{Ricardo Ferreira Freitas}

Professor do Programa de Pós-Graduação em Comunicação da Universidade Estadual do Rio de Janeiro (UERJ). $<$ rf0360@gmail.com>

\section{RESUMO}

Neste artigo, discutimos três textos de Simmel escritos para a imprensa de Berlim, inspirados em suas angústias durante a Primeira Guerra Mundial: "A ideia de Europa", publicado em 7 de março de 1915, no Berliner Tageblatt; "A Europa e a América: considerações sobre a história universal", publicado em 4 de julho de 1915, no Berliner Tageblatt; e "Bergson e o 'cinismo' alemão", publicado em 1 de novembro de 1914, no Internationale Wochenschrift für Wissenschaft, Kunst und Technik. Os textos de Simmel para a imprensa constituem-se em importante material de estudos em comunicação, devido à liberdade com que Simmel se expressa ao público em geral, sem abandonar os conceitos fundamentais de sua sociologia. Um dos resultados desta pesquisa aponta o conflito como um componente fundamental aos processos de comunicação, visto que o dissenso, a discórdia e o combate implicam a compreensão dos códigos de cada parte.

Palavras-chave: Simmel. Primeira Guerra Mundial. Comunicação.

\begin{abstract}
In this article, we will discuss three articles wriiten by Georg Simmel for the Berlin press, driven mainly by his anguish toward the First World War: "The Idea of Europe", published on March 7h, 1915 in the Berliner Tageblatt, "Europe and America in World History", published on November 1st, 1914 in the Internationale Wochenschrift fur Wissenschaft, Kunst und Technik. Simmel's production for the press presents an important source of material for communication studies, specially because of the freedom from which Simmel addresses the general public, without abandoning the fundamental concepts of Sociology. One result of this research shows the conflict as a key component to communication processes, since dissent, disagreement and struggle imply the understanding of communication codes from both parts.
\end{abstract}

Keywords: Simmel. First World War. Communication.

Introdução

[...] A importância histórica de Simmel está no fato de que ele foi, desde o começo, o representante mais marcante do pluralismo metodológico. O pathos do seu filosofar tinha sua origem na consciência pasma com as possibilidades múltiplas de enunciação e objetividade filosóficas. "Há muito poucas categorias, do mesmo

1 Pesquisa financiada pela CAPES e pela UERJ. 
modo que existem muito poucos sexos", disse ele uma vez numa conversa. Essa sentença assinala, ao mesmo tempo, com uma nitidez marcante, os limites de seu ser (Lukács, 2006, p. 205).

O pensador alemão Georg Simmel (1858-1918) tem sido cada vez mais incluído nos estudos da comunicação, da sociologia e da filosofia no Brasil, e em vários outros países, sobretudo a partir de 1980. Um dos motivos dessa redescoberta reside na maneira de Simmel interpretar a interação, ação recíproca entre os indivíduos, como um importante objeto das ciências humanas, podendo assumir várias formas, como conflito, cooperação, competição, submissão, entre outros. "As formas sociais são configurações momentâneas de um complexo de movimentos. Daí Simmel preferir falar em sociação que em sociedade" (Castro, 2014, p. 39). As relações entre os indivíduos e entre os fatos sociais não acontecem em um sentido único. Assim, cada fenômeno social é composto de pelo menos uma ação e uma reação (Bruno e Guinchard, 2009).

O conflito é um componente fundamental aos processos de comunicação, visto que o dissenso, a discórdia e o combate implicam a compreensão da leitura dos códigos das partes envolvidas. A comunicação, no seu sentido mais primário, impõe a tentativa de compreensão do que o outro diz, das suas formas de narrar o que pensa e explicitar seus desejos, gerando as mais diversas interpretações. Muitas vezes, é com o conflito que as partes envolvidas desenvolvem novas formas de comunicação, algumas pacíficas, outras bélicas. Simmel é um dos autores clássicos da sociologia que pode nos ajudar a compreender esse fenômeno, visto haver desenvolvido uma longa teoria sobre o conflito. Neste artigo, optamos por seu olhar sobre a guerra para propor uma outra visão sobre os processos de integração e de discórdia.

Sua perspicácia intelectual o leva, na França e na Alemanha, entre 1894 e 1897, a alcançar uma notoriedade maior do que a de Weber, nas revistas de sociologia e filosofia, mas a partir da Primeira Grande Guerra passa a ser menos mencionado. Alvo do antissemitismo, Simmel também irrita a academia pelo seu inconformismo e seu enorme sucesso de público. A organização universitária formal que representa as instituições clássicas (a família, as Igrejas e o Estado) não consegue lidar com suas conferências, em auditórios sempre lotados, nas quais relativiza o poder absoluto dessas instituições (Bruno e Guinchard, 2009).

Seu retorno às teses de sociologia no ocidente só se intensificará bem após a Segunda Guerra, devido ao desprezo ao povo judeu manifestado nas décadas anteriores em vários países (Bruno e Guinchard, 2009). O filósofo 
português José Luís Garcia (2007) ressalta que, durante e imediatamente depois da Segunda Guerra Mundial, Simmel não exerceu, nem na Alemanha, nem nos EUA, uma influência comparável àquela que obteve no tempo em que viveu. Mesmo sendo contemporâneo de Durkheim e de Weber, sua presença intelectual posterior foi bem menos expressiva que a desses dois grandes pensadores (Garcia, 2007). Em sua época, só conquistou uma cátedra de titular em sociologia poucos anos antes de morrer, na Universidade de Estrasburgo, devido a oposições antissemitas que Ihe dificultaram a ascensão. No entanto, Simmel teve papel destacado no estabelecimento da sociologia como disciplina autônoma e uma importância ímpar na reflexão sociológica e filosófica do período anterior à Primeira Guerra Mundial (Garcia, 2007).

Com diagnósticos argutos sobre seu tempo, Simmel reaparece nas pesquisas contemporâneas, também por haver refutado a tendência moderna de exaltar o fim da liberdade de pensamento e, ao contrário, ter acreditado na fragilidade dos sentidos absolutos da vida, especialmente nas metrópoles (Vandenberghe, 2001). A vida do cidadão não é só um processo de envelhecimento fisiológico, ela é o destino contínuo e criador que ele experimenta todos os dias de sua existência.

Simmel aprecia o pensamento construído no cotidiano, com os sentidos provocados pelas experiências imediatas e com os movimentos dos corpos, das opiniões e das intuições. O pensamento vivido impõe que os limites, ao serem reconhecidos, sejam ultrapassados. Esses ingredientes valorizados por Simmel, em sua herança teórica, são fundamentais aos estudos das teorias da comunicação contemporânea, obrigando-nos, ou melhor, alegrando-nos a debruçar sobre sua obra. O cotidiano é um importante panorama para seus estudos, com especial atenção aos processos discretos e microscópicos da interação social.

Suas ideias intensas sobre a cultura e a sociedade, muitas vezes em forma de ensaios, o desamarraram dos medos e hesitações da academia universitária do final do século XIX. Contando com sensibilidade e intuição ao elaborar seu pensamento, Simmel saiu dos muros das instituições de pesquisa (Jankélévitch, 1988) ao analisar, com intensidade inédita, questões presentes no cotidiano das metrópoles que não eram consideradas essenciais à academia formal, como a prostituição feminina, a moda, o dinheiro e o amor, entre outras. 


\section{Simmel face à Primeira Grande Guerra}

[...] O próprio conflito resolve a tensão entre contrastes. O fato de almejar a paz é só uma das expressões - e especialmente óbvia de sua natureza: a síntese de elementos que trabalham juntos, tanto um contra o outro, quanto um para o outro. Essa natureza aparece de modo mais claro quando se compreende que ambas as formas de relação - a antitética e a convergente - são fundamentalmente diferentes da mera indiferença entre dois ou mais indivíduos ou grupos. Caso implique a rejeição ou o fim da sociação, a indiferença é puramente negativa; em contraste com esta negatividade pura, 0 conflito contém algo de positivo. Todavia, seus aspectos positivos e negativos estão integrados; podem ser separados conceitualmente, mas não empiricamente (Simmel, 1983, p. 123).

Neste artigo, priorizamos seus textos escritos para a imprensa de Berlim, pouco conhecidos pelo público brasileiro, inspirados em questões e angústias levantadas durante a Primeira Guerra Mundial (1914 - 1918), momento em que alguns países europeus elegeram o combate bélico como solução para os conflitos econômicos, territoriais, políticos e religiosos que viviam. Lembramos que, assim como a Segunda Guerra Mundial, a Primeira deixou sequelas profundas na história da Europa e do Mundo. Na França, não à toa, o Dia do Armistício, 11 de novembro, é um importante feriado que provoca várias reportagens e discussões nos jornais e nos canais públicos de televisão.

Simmel vê na guerra os antagonismos da cultura da época e a efervescência dos debates que não se podem calar nem de um lado nem do outro. A guerra implica o conflito, o combate, a competição e a concorrência, conceitos caros à sua forma de interpretar a sociedade. Essa tensão é abordada nos textos selecionados, com elementos de emoção e de cumplicidade com seus admiradores. Simmel acredita na imprensa como forte parceira de difusão da sua maneira de pensar, apesar de ter sido, muitas vezes, um de seus maiores antagonistas.

Esses textos, assim como as conferências proferidas pelo pensador à época, revelam um intelectual mais preocupado com seus leitores e ouvintes do que com o grande público intelectual que o acompanhava nesse período. Referimo-nos à atitude inquieta do pensador, à sua agilidade em abordar o real sob diversos pontos de vista, provocando-os a dialogar, por mais heterogêneos que sejam, sem pretender chegar a conclusões definitivas. Os diferentes pontos de vista, afinal, formam a sociedade. 
Nesse sentido, elegemos, para análise, três artigos escritos em 1914 e 1915: "A ideia de Europa", publicado em 7 de março de 1915, no Berliner Tageblatt; "A Europa e a América: considerações sobre a história universal", publicado em 4 de julho de 1915, no Berliner Tageblatt; e "Bergson e o 'cinismo' alemão", publicado em 1 de novembro de 1914, no Internationale Wochenschrift für Wissenschaft, Kunst und Technik.

Para a leitura desses três artigos, utilizamos como base o livro "Georg Simmel face à la guerre" (2015), editado em francês pelo pesquisador em cultura germânica Jean-Luc Evard, filósofo político e profundo conhecedor da história do antissemitismo e das experiências geopolíticas do cidadão judeu. Nessa obra, Evard apresenta oito artigos sobre a Primeira Guerra, escritos por Simmel entre 1914 e 1916. A ordem dos três textos escolhidos não está baseada em um fator cronológico, mas acompanha a relação que Evard estabeleceu no índice apresentado em seu livro. Na análise aqui proposta, esses escritos estão resumidos e comentados, mantendo, no entanto, 'o espírito' de Simmel na arte de sua narrativa.

Nos artigos selecionados, Georg Simmel deixa claro, apesar de sua decepção com a destruição, que a eclosão da Primeira Guerra foi fruto de uma tensão que se desenvolvia entre as nações da Europa desde o século XIX, com forte influência dos Estados Unidos. Um tipo de situação que acontece na história da humanidade quando os movimentos coletivos transformam os indivíduos, intensificando o elo entre eles. Simmel acredita que o povo alemão, inconscientemente, precisava de uma saída para repensar a modernidade e as consequências do lluminismo. A guerra o incomodou, mas, ao mesmo tempo, serviu como inspiração para uma nova gama de pensamentos provocadores e, muitas vezes, ácidos.

\section{A ideia de Europa - 7 de março de 1915}

Nesse texto, Simmel argumenta que a guerra sempre é um paradoxo. Conjunto de contradições em forma de surto ou de epidemia que acomete os povos, como, por exemplo, o flagelo da Inquisição na Idade Média ou as grandes invasões europeias na África, especialmente as do século XIX. Com a tentação da dominação do continente africano, as potências europeias desenvolveram uma corrida massiva aos países daquele continente e ocuparam vários deles, criando neocolônias. Esse momento é marcado pelo ressurgimento ou aparecimento de novas potências concorrentes, como a Alemanha, a Bélgica e a Itália. 
As antigas civilizações impuseram devastações insensatas com o roubo de tesouros superabundantes, que ainda hoje são exibidos em importantes museus da Europa. É difícil fornecer respostas contundentes a essas invasões, o que só aumenta o embaraço teórico, segundo Simmel, para compreender ou explicar essas epidemias. Incômodos que habitarão o imaginário dos tempos de paz que um dia virão, após a Guerra. Simmel não presumia, nesse artigo, que haveria uma Segunda Guerra ainda mais insensata e contraditória, mas tampouco acreditava em um futuro sem guerras no mundo.

Para Simmel, a época da Primeira Guerra só traz uma certeza à Alemanha: dar sentido político à destruição, acreditando que tudo se ajeitará após a insensatez das atitudes destruidoras e revanchistas. $O$ espírito do sacrifício, em nome da guerra, não implica valores nobres no extermínio do inimigo. Mesmo que na França, por exemplo, o sentimento de patriotismo crescesse com a guerra, não se podia ter a certeza que o conjunto do povo havia escolhido ou apoiado essa opção. França e Alemanha vivem, durante a Guerra, a inacreditável polaridade de valores cívicos e humanos que tentam justificá-la.

Com a guerra, perdem-se as pessoas queridas, mas também a unidade orgânica espiritual chamada de "Europa" (Evard, 2015). Nesse momento, Simmel se questiona se essa unidade poderá ser restabelecida algum dia, mas, ao mesmo tempo, acredita que o conflito instituirá novos tempos de esperança ao continente.

A Europa ideal, para ele, é um lugar de valores supra-históricos que absorvem as fruições mais íntimas, não necessariamente se configurando como um organismo internacional. É uma ideia baseada nas intuições construídas ao longo do passado e do presente. O colorido único das fontes espirituais modernas de seus povos contrasta, mas dialoga, com o espírito greco-romano da Antiguidade e com a ideia ecumênica católica da Idade Média. Uma Europa imortal, mas vulnerável na sua unidade.

Para Simmel, não é somente necessário "que a ideia de Europa não possa morrer" (Evard, 2015, p. 12), é necessário, sobretudo, que ela possa sobreviver. Nesse sentido, Simmel acredita que a guerra é mais viril que a fantasia da união, visto que o ódio no continente europeu alienou os espíritos e, mesmo entre os neutros, a tendência foi de aceitar o conflito e encará-lo como inevitável, ou como uma questão de honra. A Europa, nesse momento da história, não soube, segundo Simmel, consolidar a concepção do "bom europeu", a despeito do orgulho internacional que ela poderia provocar em seus habitantes.

É importante deixar claro que, nesse artigo para a imprensa, o sociólogo não se distancia de sua ideia sobre o individualismo, baseada na permuta 
interacional entre cidadãos livres, permitindo a ampliação da distinção entre eles e nos grupos e arranjos sociais por eles organizados, o que intensifica a relação e a vida na cidade.

Simmel acredita, e foi bastante mal interpretado a posteriori, que aí reside o reconforto da guerra: as perdas serão o principal elemento da memória da desunião, levando os indivíduos a pensarem em si próprios e transformando essa energia para um dia poder viver outra vez a Europa, nem necessariamente ser uma causa só alemã. O rancor e a discórdia, assim como em uma família que fecha as portas a seus filhos, poderão trazê-los de volta mais maduros ou mais resistentes a algumas memórias. Simmel esperava que em algum momento viria o dia da reconciliação, reabrindo essas portas, apesar do sangue que as fechou. $\mathrm{O}$ ensinamento do conflito e do sofrimento poderia religar e restaurar a comunidade destruída.

A guerra é, nessa visão simmeliana, a possibilidade de um recomeço, demonstrando que os partidos políticos e seus líderes não servem mais à vontade de seus povos. Tampouco a guerra deixará de estimular novas religiões e seus dogmas, muitas vezes fazendo ressurgir o lado mais cruel dos homens. Simmel encarou essa crise social, esse conflito, como uma questão cultural, interpretando os lados desse fato histórico de forma dicotômica primária, mas, como sempre, astuta: o lado verdadeiro do fato histórico e o lado falso do mesmo fato.

Segundo ele, o fato histórico é verdadeiro, já que os comportamentos sócio-culturais estigmatizados por ele se referem especificamente a uma outra Alemanha, diferente da que se apresenta na guerra, mas sobretudo a uma Europa que teria compreendido não poder mais se ater a um cosmopolitismo baseado nas trocas impostas pelo dinheiro. Para além das questões puramente monetárias, há os aspectos culturais dos quais o próprio dinheiro faz parte. Por outro lado, o fato histórico também é falso, já que essa crítica reside sobre uma economia monetária até então inexorável (Watier, 2003). O termo "economia monetária" é utilizado por Simmel no lugar de capitalismo, mas representa mais do que isso, já que corresponde a uma perspectiva histórica de longa duração na qual, para além dos diferentes sistemas econômicos que tenham existido, desenvolve-se um processo de monetarização indutor dos sistemas de modernização e civilização da sociedade (Bruno e Guinchard, 2009). Nesse sentido, a Alemanha, durante a guerra, demonstra um egocentrismo que explica a naturalidade do povo em encarar o conflito como um momento essencial ao futuro da nação alemã, poderosa e economicamente líder. 
A Europa e a América: considerações sobre a história universal - 4 de julho de 1915

Nesse artigo, Simmel demonstra continuar acreditando na ideia de Europa unida, apesar de rachada pela momentânea guerra. No entanto, ele vê os Estados Unidos como um possível aproveitador da fraqueza momentânea da Europa. Segundo ele, a Alemanha não é só o território germânico, mas sobretudo uma parte essencial da Europa, especialmente aos olhos das outras potências do mundo (Evard, 2015). Daí o Fator Europa ser dotado de uma espécie de solidariedade marcada, tendo a Alemanha como uma de suas protagonistas. No entanto, no momento da guerra, o Fator Europa passa a ser dotado de signos negativos, em uma luta que despedaça o continente. Uma Europa à beira do suicídio na qual a América vê a oportunidade de se lançar como líder dos negócios no mundo, como herdeiro fúnebre que se regozija sobre o leito da morte dos países europeus.

A Europa exportava para a América um capital considerável de frutas oriundas de duro trabalho de seus agricultores. Esse quadro se inverte com a guerra, o que acelera ainda mais a industrialização e o desenvolvimento científico dos Estados Unidos. Além dos alimentos, as vendas de armas e outros artefatos de guerra não são para os Estados Unidos somente um negócio ordinário, mas sim uma forma de acelerar, em direção ao oeste, as bússolas de poder político do universo. A uma parte dos povos europeus (Tríplice Entente), eles enviam suas armas que, na verdade, enfraquecem o conjunto da Europa, segundo Simmel.

Aliada da França na Tríplice Entente, a Inglaterra era considerada por alguns intelectuais da época como a responsável pelo apoio dos Estados Unidos contra o grupo liderado pela Alemanha. Simmel não imputa a atitude americana à sua relação histórica e genealógica com a Inglaterra. Na verdade, era a Europa que estava em questão e isso implicava tanto Inglaterra como Alemanha.

Nesse artigo, Simmel demonstra não ter dúvidas de que a América empregaria o mesmo zelo ao vender suas armas às outras potências se fosse necessário e mais lucrativo trocar de lado, visto que se prestaria ao mesmo propósito: a destruição da Europa. Os Estados Unidos poderiam, então, optar por um procedimento cujo caráter formal da neutralidade não mudaria em nada a sua atitude atual, a despeito de seus possíveis, porém improváveis, ideais humanitários. Mas a preponderância de sua classe dirigente não inibiria as infidelidades em nome de vantagens mercantis a curto e médio prazos, como ressalta Simmel ao lembrar as palavras do Presidente Wilson de que a América não apoia um lado ou outro, mas, sim, a própria América. No ponto de vista do 
pensador, ao soprar sobre as brasas dessa guerra, os Estados Unidos não agem contra um campo político específico, mas contra a Europa como um todo. Para Simmel, essa articulação se configurou como uma obra-prima da especulação perversa da história universal (Evard, 2015).

No artigo, Simmel se pergunta se a Europa seria, portanto, tão demente a ponto de cometer esse suicídio. Esperançoso, acredita que a Alemanha sairia revigorada dessa guerra - ele não se refere aos mortos, afirmando que nada os substituirá - e que tudo perdido voltaria multiplicado ao país, enquanto o resto da Europa ficaria enfraquecida. Com a França, especificamente, a Alemanha tinha um duelo a combater, ao se referir a Alsácia, que ele acreditava que seu país conservaria².

Por outro lado, Simmel afirma, mais uma vez, que o conjunto da Europa unida é a única solução para um equilíbrio no mundo, tantos nos aspectos econômicos quanto culturais. Simmel, tomado pelas emoções do momento, demonstra algumas contradições em seu texto já que, ao mesmo tempo, prevê uma Europa enfraquecida, mas defende uma Europa unida, de modo a ser forte o suficiente para combater o imperialismo norte-americano ou mesmo uma prevalência do poderio asiático sobre o mundo. Remetendo-nos a sua natureza sociológica do conflito, percebemos que, nesse artigo para a imprensa, Simmel se refere ao tipo social de conflito das comunidades mais globais (Bruno e Guinchard, 2009). Nesse tipo social, o combate é uma força integradora na medida em que permite os grupos sociais, e os indivíduos que os compõem, a reforçar seus sentimentos de pertencimento e, assim, melhor definir sua posição de reciprocidade ao seio do grupo.

\section{Bergson e o "cinismo" alemão - 1 de novembro de 1914}

Nesse artigo, escrito meses antes dos dois anteriores, Simmel demonstra seu descontentamento com o jornal francês "Le Petit Parisien", pela cobertura de uma conferência proferida por Henri Bergson na Academia Francesa. Nessa conferência, Bergson evocou o cinismo com o qual a Alemanha começou a

2 A Alsácia-Lorena é um território de população com forte influência germânica, originalmente pertencente ao Sacro Império Romano-Germânico tomado por Luís XIV da França em 1648, mas devolvido pela França à Alemanha em 1871, após a Guerra Franco-prussiana e em seguida retomado pela França após a Primeira Guerra Mundial nos termos do Tratado de Versalhes de 1919. Foi anexado pela Alemanha durante a Segunda Guerra Mundial e retomado pela França, ao final dessa mesma guerra, em 1945. A partir de 2015, com a nova divisão regional da França, a região de ChampagneArdenne foi anexada a Alsácia-Lorena. Em francês, a nova região passou a ser denominada "Alsace/ Lorraine/Champagne-Ardenne. 
Primeira Guerra e a volta à barbárie que ela representava. Simmel, indignado com seu colega francês, declara em seu texto, de forma irônica, que apesar do jornal "Le Petit Parisien" não ser uma fonte confiável, a notícia bem que poderia ser verdadeira.

Também de família judia, Bergson (1859-1941) conta com obras já clássicas à época da Primeira Guerra como "Matéria e memória" (1896) e "A Evolução criadora" (2009). Em muitos momentos, foi parceiro de Simmel em discussões e seminários, mas foi como diplomata francês que incomodou a intelectualidade alemã ao exercer influência na intervenção dos Estados Unidos no conflito.

Simmel cita, no seu artigo, comentários de intelectuais alemães da época sobre Bergson em que o chamam de "filósofo de salão" (Evard, 2015, p. 73). Simmel refuta essa adjetivação, lembrando que Bergson costuma liderar pesquisas essenciais sobre o povo europeu, além de ser um pensador do mais alto nível intelectual. No entanto, ele se pergunta como pode um homem dessa envergadura intelectual pronunciar julgamentos tão vulgares sobre os alemães? Isso seria esperado, segundo Simmel, de um francês mediano que não conhece bem a Alemanha e sua trajetória intelectual. Mas, Bergson, que aprecia e estuda a filosofia alemã, sobretudo Kant, cuja obra conhece tão profundamente, além dele próprio (Simmel), demonstrou, nessa conferência, não compreender os alemães.

Simmel afirma que, em suas polêmicas literárias, os franceses são modelos de uma extrema competência objetiva. Mas, durante a Guerra, indaga-se inconformado: Quando justamente a marca mais importante dos últimos anos terríveis foi o fato de os alemães terem se desesperado com a própria nação, como eles podem lançar essa blasfêmia? São eles os cínicos, então (Evard, 2015).

Simmel não hesita em dizer que mesmo um espírito obtuso poderia compreender que as condições de vida haviam se complicado de maneira inconcebível, interferindo umas nas outras em um jogo perigoso de compensações, e que, no momento em que essa arquitetura política foi destruída, em plena paz, tudo se arruinou. Para Simmel, o povo alemão sabe que não haverá restabelecimento em uma só geração que alcance o nível anterior de negociações (em paz).

Nesse artigo, Simmel, apesar de sua momentânea decepção com Bergson, alimenta, como em outros textos e conferências desse período, a esperança de uma Alemanha mais unida no futuro, com mais reflexão, mais atenta aos perigos da guerra, reconhecendo também grande angústia com o atual desenho político de seu país. Preocupa-se com o desentendimento que poderá haver entre os povos europeus, para além dos perigos da situação política e militar, 
ressaltando que o coletivo, na lógica construída pela industrialização, torna-se só uma quimera quando se distancia do mundo econômico-financeiro.

No futuro, segundo ele, os europeus teriam a oportunidade de perceber que ninguém era anjo, mas que, naquele momento, as raízes da guerra, consideradas frutos de cinismo por Bergson, não faziam parte da vida dos alemães comuns. Essa guerra, sentida por cada um como o pior choque de sua existência, não poderia, para Simmel, ser assumida como um cinismo do povo alemão, especialmente, por todas as ameaças que pesavam sobre o imaginário coletivo.

Simmel afirma"nós não somos cínicos, nós simplesmente nos esquivamos, em nome de nossa dignidade e do nosso futuro" (Evard, 2015, p. 75). Para o filósofo, os verdadeiros cínicos procurariam a segurança em face dos perigos exteriores, em liberdade, distante das turbulências fortes e profundas. Os inimigos, nesse caso os franceses, não poderiam reprovar o comportamento dos alemães com nenhuma legitimidade, visto que encaravam a guerra com um patriotismo que ignorava a destruição que se dava na Europa. Em vez de compreender o espírito do momento que impunha essa energia, os franceses abriam um abismo entre os povos envolvidos.

Simmel insiste que, em resposta aos inimigos, a Alemanha deve revelar ao mundo a cultura do seu povo e mostrar que o cinismo citado por Bergson nada mais é do que uma das marcas do conflito, de uma guerra marcada pela conquista do território e do poderio econômico. Neste artigo, independentemente de seu constrangimento com Bergson, Simmel defende que a guerra se constitui, antes de mais nada, como uma grande tensão entre $o$ poder econômico e o poder ideológico, servindo, assim, para pensar a relação entre o indivíduo e a sociedade. Essa defesa dialoga com sua ideia de sociologia, baseada na socialização, o que implica uma perspectiva de troca permanente das construções sociais produzidas no cotidiano em estreita relação com as inúmeras ações recíprocas, permanentemente renováveis.

\section{Considerações finais}

A importância de Simmel para a sociologia [...] vem de que ele exacerba e aprimora a análise das condicionalidades a um ponto que ninguém havia conseguido alcançar antes dele, fazendo aparecer ao mesmo tempo, com uma nitidez inimitável, a invenção dessas relatividades, sua autolimitação, sua parada diante do 
incondicionável. A sociologia da cultura, como Max Weber, Troeltsch, Sombart e outros compreenderam, só se tornou possível - por mais fortes que sejam suas divergências metodológicas com ele - no terreno que ele soube criar (Lukács, 2006, p. 207).

Os três artigos selecionados demonstram um lado intelectual de Simmel pouco conhecido pela academia, mas coerente com o cidadão que sempre expressou seus pensamentos com grande liberdade filosófica, um dos motivos que o conservou distante dos mais expressivos cargos nas universidades alemães. Seu pensamento livre e o fato de ser judeu o mantiveram em xeque em quase toda sua vida profissional. No entanto, como assinala Lukács (2006), deixou como legado discussões fundadoras sobre a sociologia da cultura, campo de fundamental importância teórica para os estudos de comunicação.

Os textos de Simmel sobre a guerra, além de pouco divulgados, são, muitas vezes, considerados estranhos ao conjunto de sua obra, mas não podemos deixar de levar em conta o contexto histórico e geográfico no qual foram produzidos. Nos artigos selecionados, percebemos que o sociólogo, apesar de seu repúdio à morte da população e dos combatentes, acredita que a guerra implica a possibilidade de um novo cidadão europeu. Tal ideal, que pode ser compreendido como a noção de uma nova individualidade, não estaria somente ligado ao sujeito alemão, mas sobretudo ao indivíduo europeu. Daí Simmel defender a noção de "uma" Europa, ainda que se refira, à época, a uma comunidade diferente da que se desenhou nas últimas décadas do século XX, com a criação do Mercado Comum Europeu, e a integração de diversos países em torno de uma moeda única.

$\mathrm{Na}$ análise dos três artigos, entendemos que sua ideia de Europa não é uma epopeia ao patriotismo, mas, sim, uma visão utópica de um novo homem, fruto da superação daquele conflito e da tragédia da cultura. A guerra é, nesse ponto de vista, a possibilidade de um recomeço (Waisbort, 2006). Anos antes da Primeira Guerra, Simmel já desenvolvia sua teoria sobre a natureza sociológica do conflito, percebendo-o como parte integrante de seu cotidiano e não somente como um acidente na vida das pessoas.

O combate e a disputa são fatores que contribuem à formação de associações com espírito coletivo, levando Simmel a sustentar, especialmente no clássico quarto capítulo de sua obra "Soziologie", de 1908, que, em vez de ignorá-los, os dissensos devem ser vistos como possibilidade de unidade. Simmel não procura relegar o conflito a uma rede de nuances que privariam a disputa de suas características próprias. O conflito é o símbolo de uma oposição 
que pode tomar formas amenas como as dissidências, ou formas violentas como os combates, as lutas e as guerras (Freund, 1992).

A vida é feita de amizades e discórdias e é isso que impede a consolidação de um pacifismo total ou único. Afinal, os pacifistas se propõem a estabelecer a paz entre amigos, mas, não se pode esquecer que a amizade é um estado de espírito (Freund, 1992). Daí Simmel propor a paz entre inimigos, tendo o conflito como ponto de ligação para o diálogo. Nesse contexto de admissão do ponto de vista do outro, ainda que seja inimigo, a paz não pode ser um estado em total harmonia, mas, sim, obra de forças divergentes que se reconhecem reciprocamente. Simmel explicita que, ao tentar regrar um conflito, os oponentes devem ter clareza que o compromisso está em oposição à vitória (Simmel, 1992). Paz e guerra se sucedem permanentemente como duas formas antagônicas e autônomas com um objeto político comum, seja ele qual for.

O forte componente filosófico de seu pensamento, a sutileza do conceito de social com constante referência à dimensão individual, e o ecletismo dos temas escolhidos (Bruno e Guinchard, 2009) são aspectos atualmente valorizados de sua obra que foram, décadas antes, motivos para o desprezo do mundo acadêmico, especialmente na França.

Nos três artigos analisados, percebemos que Simmel compreende a modernidade não como uma atualidade eminentemente efêmera nem simplesmente um presente mais ou menos durável ou um futuro mais ou menos indeterminado, mas, sim, como uma forma social em mudança permanente que se constrói com a democratização das sociedades, a monetarização da economia e a mundialização das relações humanas (Bruno e Guinchard, 2009).

Os artigos escolhidos foram produzidos para a imprensa, o que nos inspirou a discuti-los neste trabalho, visto que Simmel escreve de forma mais propositiva nos seus ensaios para o público em geral do que nos textos puramente acadêmicos. O desconforto com os acontecimentos se confronta a sua naturalidade em expressar as ideias, mesmo que muitas vezes suas opiniões sejam contraditórias em termos de narrativa, mas não no afeto que o assunto Ihe desperta. A espontaneidade de Simmel, sempre zeloso ao imediatismo das metrópoles, é justamente o que nos interessa em consolidar sua inclusão nos estudos da comunicação, sobretudo em uma época em que a noção de rede é, mais do que nunca, uma questão fundamental do cotidiano em todos os níveis e planos midiáticos. O conflito é, afinal, um importante valor-notícia das comunicações contemporâneas. Não à toa, em épocas de guerra, os intelectuais sempre são chamados a tentarem esclarecer o fenômeno, tanto na imprensa como nos órgãos públicos e privados. 


\section{Referências bibliográficas}

BERGSON, Henri. A evolução criadora. São Paulo: UNESP, 2009.

BRUNO, Alain; GUINCHARD, Jean-Jacques. Georg Simmel: Vie, oeuvres, concepts. Paris: Ellipses, 2009.

CASTRO, Celso. Textos básicos de sociologia. Rio de Janeiro: Zahar, 2014.

EVARD, Jean-Luc. Georg Simmel - Face à la guerre, écrits 1914-1916. Paris: Editions Rue d'Ulm, 2015.

FREUND, Julien. “Préface". In: Simmel, Georg. Le conflit. Paris: Circé, 1992.

GARCIA, José Luís. Sobre as origens da crítica da tecnologia na teoria social: Georg Simmel e a autonomia da tecnologia. Scientiae Studia, v. 5 n. 3 São Paulo, July/ Sept. 2007.

JANKÉLÉVITCH, Vladimir. Georg Simmel: La tragédie de la culture et autres essais. Paris: Rivages, 1988.

LUKÁCS, Georg. "Posfácio". In: SIMMEL, Georg. Filosofia do Amor. São Paulo: Martins Fontes, 2006.

MORAES FILHO, Evaristo de. Simmel. Coleção Grandes Cientistas Sociais. São Paulo: Ática, 1983.

SIMMEL, Georg. A natureza sociológica do conflito. In: Moraes Filho, Evaristo (org.). Simmel. São Paulo: Ática, 1983.

Le conflit. Paris: Circé, 1992.

Soziologie. Berlim: Duncker e Humblot, 1908. Disponível em: <http://www. socio.ch/sim/soziologie/soz 4.htm>. Acesso em: 21 nov. 2015.

VANDENBERGHE, Frédéric. La sociologie de Georg Simmel. Paris: La Découverte, 2001.

WAISBORT, Leopoldo. As aventuras de Georg Simmel. São Paulo: Editora 34, 2006.

WATIER, Patrick. Georg Simmel - sociologue. Belval: Circé/Poche, 2003.

Recebido em: 10/03/2016

Aceito em: 10/03/2016

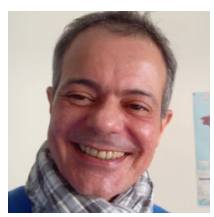

Endereço do autor:

Ricardo Ferreira Freitas <rf0360@gmail.com>

http://lattes.cnpq.br/4330637331534162

Programa de Pós-Graduação em Comunicação da Universidade Estadual do Rio de Janeiro (UERJ).

Rua São Francisco Xavier, 524, $10^{\circ}$ andar, sala 10.121, bloco F, Pavilhão João Lyra Filho

20550-900 - Maracanã - Rio de Janeiro - RJ - Brasil 